\title{
Drought fluctuations based on dendrochronology since 1786 for the Lenglongling Mountains at the northwestern fringe of the East Asian summer monsoon region
}

\author{
HOU Ying ${ }^{1,2 *}$, NIU Zhenmin ${ }^{2}$, ZHENG Fang $^{1}$, WANG Nai' ang ${ }^{2}$, WANG Jianyu ${ }^{1}$, \\ LI Zhuolun ${ }^{2}$, CHEN Hongxiang ${ }^{1}$, ZHANG Xuemin ${ }^{2}$ \\ ${ }^{1}$ College of Earth and Environmental Sciences, Ningxia University, Yinchuan 750021, China; \\ ${ }^{2}$ Center for Climate Change and Hydrologic Cycle in Arid Region, College of Earth and Environmental Science, Lanzhou \\ University, Lanzhou 730000, China
}

\begin{abstract}
The Lenglongling Mountains (LLM) located in northeastern part of the Tibet Plateau, belong to a marginal area of the East Asian summer monsoon (EASM) and are sensitive to monsoon dynamics. Two tree-ring width chronologies developed from six sites of Picea crassifolia in the LLM were employed to study the regional drought variability. Correlation and temporal correlation analyses showed that relationships between the two chronologies and self-calibrated Palmer Drought Severity Index (sc_PDSI) were significant and stable across time, demonstrating the strength of SC_PDSI in modeling drought conditions in this region. Based on the relationships, the mean Sc_PDSI was reconstructed for the period from 1786 to 2013. Dry conditions prevailed during 1817-1819, 1829-1831, 1928-1931 and 1999-2001. Relatively wet periods were identified for 1792-1795 and 1954-1956. Spatial correlations with other fourteen precipitation/drought reconstructed series in previous studies revealed that in arid regions of Northwest China, long-term variability of moisture conditions was synchronous before the 1950s at a decadal scale (1791-1954). In northwestern margin of the EASM, most of all selected reconstructions had better consistency in low-frequency variation, especially during dry periods, indicating similar regional moisture variations and analogous modes of climate forcing on tree growth in the region.
\end{abstract}

Keywords: dendrochronology; East Asian summer monsoon region; self-calibrated Palmer Drought Severity Index; Lenglongling Mountains

Citation: HOU Ying, NIU Zhenmin, ZHENG Fang, WANG Nai'ang, WANG Jianyu, LI Zhuolun, CHEN Hongxiang, ZHANG Xuemin. 2016. Drought fluctuations based on dendrochronology since 1786 for the Lenglongling Mountains at the northwestern fringe of the East Asian summer monsoon region. Journal of Arid Land, 8(4): 492-505. doi: $10.1007 / \mathrm{s} 40333-016-0009-8$

Drought and desertification have caused increasing concerns related to their long-term and wide-ranging effects on the economy and the environment (Wang, 2004; Wang et al., 2009; Leng et al., 2015). However, available historical records do not provide an adequate temporal scale for the identification of the patterns of the emergence of dry/wet events and the possible causes of long-term climate change (Nicault et al., 2008). Compared with most paleoclimatic proxy indices, tree-ring records have the advantages of providing relatively high-resolution and annual time-series of data that can be used to calibrate the relationships between climate and proxy data

*Corresponding author: HOU Ying (E-mail: holying@foxmail.com)

Received 2015-10-25; revised 2016-02-25; accepted 2016-03-03

(C) Xinjiang Institute of Ecology and Geography, Chinese Academy of Sciences, Science Press and Springer-Verlag Berlin Heidelberg 2016 
(Fritts, 1976; Cook et al., 1999). All these show that using tree-ring data as a proxy of climate change and calculating the climatic conditions from an equation is feasible (Nicault et al., 2008; Büntgen et al., 2010; Yang et al., 2014; Cai et al., 2015; Gou et al., 2015a; Tei et al., 2015).

The East Asian monsoon is an important component of the Earth's climate system; it plays an important role in the distribution of seasonal rainfall in eastern China (Qian et al., 2009; Zhou and Huang, 2010). The areas that lie on the margins of East Asian summer monsoon (EASM) are the most fragile ecological transitional zones of China while serving as important farming-grazing areas. Meanwhile, these areas show significant dry/wet variations caused by the advance and retreat of rain-band movement regulated by the EASM. Therefore, these areas of China would profit from a study of past climate and vegetation changes because of their sensitivity to environmental change and human activity (Ding et al., 2008; Zhao and Yu, 2012). Based on multi-year tree-ring samples from these areas, we knew an effective paleoclimatological proxy that can be used to reconstruct annual monsoon precipitation rates over centuries and to possess tremendous potential for use in climate research (Liu et al., 2003, 2008; Chen et al., 2013; Gao et al., 2013; Yang et al., 2014; Cai et al., 2015).

The Lenglongling Mountains (LLM), located in northeastern part of the Tibet Plateau and at northwestern fringe of the EASM, are typical of environmentally sensitive and vulnerable landscapes. These mountains provide the source of the Shiyang River that flows towards northeast, irrigates agricultural fields of the Minqin Oasis and eventually disappears in the desert. Uneven seasonal runoffs, unreasonable development and irrigation have caused a series of environmental problems in the Shiyang River Basin, such as the excessive extraction of groundwater, land desertification and the rapid shrinking of oases ( $\mathrm{Su}$ et al., 2014; Zhu and Li, 2014). Hence, studying dry/wet variations in the water source area during the past several hundred years by tree-ring records provides scientifically sound data and reference values related to water resource protection and the development of a sustainable economy in the basin.

However, compared with past dendroclimatic researches in the Heihe and Shule rivers over the Hexi Corridor (Liu et al., 2009; Tian et al., 2009; Zhang et al., 2011; Yang et al., 2012; Deng et al., 2013), currently published research is not sufficient to fully reveal the characteristics of hydroclimatic variation in the water source area of the Shiyang River and the possible mechanisms related to this variation. The purposes of this work were to (1) examine the main climatic factors limiting the tree growth; (2) examine the evolution of drought variability in the LLM through a 228-year self-calibrated Palmer Drought Severity Index (sc_PDSI) reconstruction derived from accurately dated and annually resolved tree-ring data; and (3) discuss the inter-annual and decadal dry/wet variation trends in the northwest margin of the EASM and the arid region of Northwest China.

\section{Materials and methods}

\subsection{Tree-ring materials}

The six sampling tree-ring sites are located in the LLM; two of them are located in the eastern mountains which are only about $12 \mathrm{~km}$ to the south near the Tengger Desert (Fig. 1). The mean annual precipitation ranges from 183 to $410 \mathrm{~mm}$ from the east to the west of the mountains. Using currently standard dendrochronological methods (Fritts, 1976; Cook and Kairiukstis, 1990), we extracted a total of 249 increment cores from 125 living trees (Picea crassifolia) with standard increment borers. All sites had poorly developed soil, sparse vegetation cover and a low density of trees on steep rocky slopes. Table 1 provides information for each site. Tree core samples were mounted, air dried and polished with fine abrasive papers. Tree core were measured to the nearest $0.001 \mathrm{~mm}$ with a LINTAB width measurement system (Rinntech, Heidelberg, Germany), and cross-dated by visual growth pattern matching and statistical tests in the TSAP software package (Rinn, 2003). Ring-width measurement series were re-checked for possible dating errors using the COFECHA quality control software (Holmes, 1983). Next, ring-width series that were not significantly correlated to the group were removed from the data set.

Because all tree-ring cores from neighboring sites agree well with each other (as indicated 
by a mean value of serial inter-correlation of 0.7 ; Table 1), all ring-width series in the western mountains could be merged to develop one robust composite chronology (WLL) for improving sample replication. Each series was detrended with a cubic smoothing spline with a $50 \%$ frequency response at $67 \%$ of the series length (Cook and Peters, 1981; Table 1). Meanwhile, all series in eastern mountains were standardized into a new composite chronology (ELL) with a Hugershoff growth curve or straight lines to mitigate non-climate effects using the program ARSTAN (Cook and Holmes, 1984; Table 1). In addition, standardized chronologies were used in all subsequent analyses for preserving trends that might relate to low-frequency oscillations in climate. Expressed population signal (EPS) values were calculated for each chronology as a guide in evaluating chronology reliability (Wigley et al., 1984), with a threshold value of 0.85 to determine the reliable period for adequate sample size in chronology development.

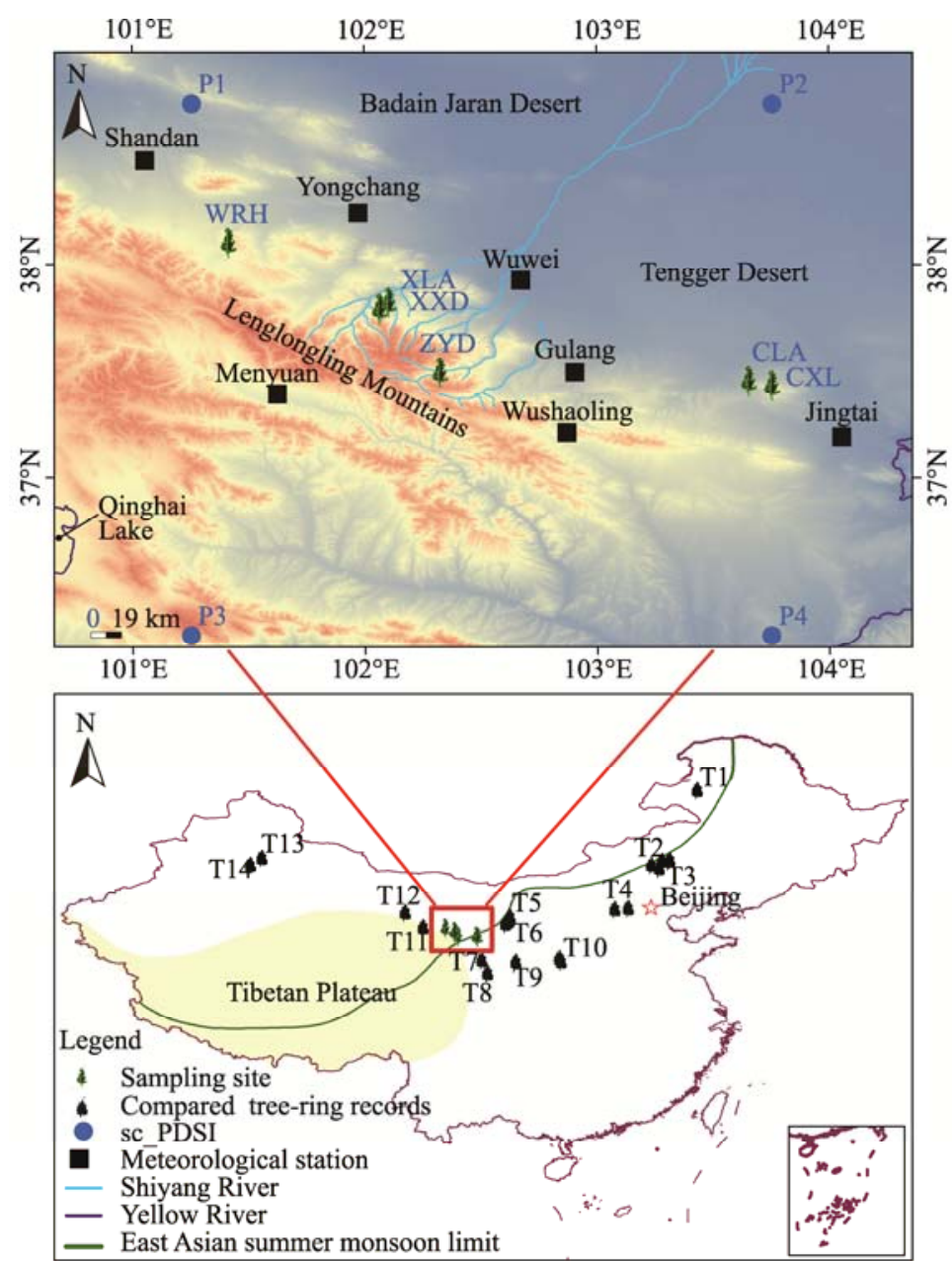

Fig. 1 Sampling sites and corresponding self-calibrated Palmer Drought Severity Index (sc_PDSI) grids. Other available drought reconstructions, their associated sampling sites are also shown (black tree). Green line indicates northern fringe of the East Asian summer monsoon region (Tang et al., 2007; Yang et al., 2014). XXD, XLA, ZYD, WRH, CLA and CXL indicate the sampling sites.

\subsection{Climate data}

Tree-ring width data were compared with monthly precipitation and mean temperature data which were obtained from nearby meteorological stations (Fig. 1). Wushaoling station was selected for subsequent analyses because it was closest in elevation to the sampling sites, and Jingtai station was also considered because of its very close proximity to the ELL chronology (Table 1). The mean annual precipitation of Wushaoling and Jingtai stations is 411 and $183 \mathrm{~mm}$, and the temperature of these two stations is $0.1^{\circ} \mathrm{C}$ and $8.7^{\circ} \mathrm{C}$, respectively. 
Because droughts in arid and semi-arid regions are linked to both a lack of precipitation and high evaporation, the Palmer Drought Severity Index (PDSI) which takes soil moisture availability into account was also considered in this study (Palmer, 1965). A PDSI dataset on a $2.5^{\circ} \times 2.5^{\circ}$ grid that was developed by Dai et al. (2004) had been widely used as the variable of climate reconstructions (Cook et al., 2004; Nicault et al., 2008; Peng and Liu, 2013; Gou et al., 2015b). The newly revised sc_PDSI index improves its ability to measure changes in aridity and to examine the effects of individual forcing on the aridity trend (Dai, 2012). In this study, four grid points of sc_PDSI nearby study areas were chosen to detect the growth response to moisture conditions (Fig. 1), and all data were available through the National Oceanic and Atmospheric Administration (NOAA) online archive.

Table 1 Information for tree-ring sites and meteorological stations

\begin{tabular}{|c|c|c|c|c|c|c|c|}
\hline Site & $\begin{array}{l}\text { Latitude and } \\
\text { longitude }\end{array}$ & $\begin{array}{l}\text { Elevation } \\
\quad(\mathrm{m})\end{array}$ & Time interval & $\begin{array}{l}\text { Cores/ } \\
\text { trees }\end{array}$ & $\begin{array}{l}\text { Average series } \\
\text { inter-correlation }^{\mathrm{a}}\end{array}$ & $\begin{array}{c}\text { Average } \\
\text { mean } \\
\text { sensitivity }\end{array}$ & $\begin{array}{l}\text { Frequency } \\
\text { of missing } \\
\text { rings (\%) }\end{array}$ \\
\hline WRH & $\begin{array}{l}38.09^{\circ} \mathrm{N} \\
101.41^{\circ} \mathrm{E}\end{array}$ & $2,806-2,900$ & 1785-2013 & $36 / 20$ & 0.73 & 0.21 & 0.10 \\
\hline XXD & $\begin{array}{l}37.81^{\circ} \mathrm{N} \\
102.01^{\circ} \mathrm{E}\end{array}$ & $2,879-2,950$ & $1877-2008$ & $42 / 22$ & 0.80 & 0.29 & 0.17 \\
\hline XLA & $\begin{array}{l}37.78^{\circ} \mathrm{N} \\
102.06^{\circ} \mathrm{E}\end{array}$ & $2,764-2,880$ & $1877-2008$ & $34 / 20$ & 0.78 & 0.21 & 0.08 \\
\hline ZYD & $\begin{array}{l}37.48^{\circ} \mathrm{N} \\
102.32^{\circ} \mathrm{E}\end{array}$ & $2,940-3,049$ & 1824-2007 & $30 / 15$ & 0.76 & 0.19 & 0.09 \\
\hline CLA & $\begin{array}{l}37.44^{\circ} \mathrm{N} \\
103.65^{\circ} \mathrm{E}\end{array}$ & $2,511-2,617$ & $1858-2008$ & $33 / 17$ & 0.67 & 0.31 & 0.07 \\
\hline CXL & $\begin{array}{l}37.42^{\circ} \mathrm{N} \\
103.75^{\circ} \mathrm{E}\end{array}$ & $2,668-2,766$ & 1860-2008 & $29 / 16$ & 0.72 & 0.28 & 0.24 \\
\hline WLL $^{\mathrm{b}}$ & & & $1786-2013$ & $101 / 62$ & 0.70 & 0.26 & 0.09 \\
\hline ELL ${ }^{\mathrm{c}}$ & & & $1867-2008$ & $50 / 25$ & 0.80 & 0.38 & 0.14 \\
\hline Wushaoling ${ }^{\mathrm{d}}$ & $\begin{array}{l}37.2^{\circ} \mathrm{N} \\
102.87^{\circ} \mathrm{E}\end{array}$ & 3,045 & $1951-2013$ & & & & \\
\hline Jingtai $^{\mathrm{d}}$ & $\begin{array}{l}37.18^{\circ} \mathrm{N} \\
104.05^{\circ} \mathrm{E}\end{array}$ & 1,631 & $1957-2013$ & & & & \\
\hline
\end{tabular}

Note: a , calculated using the computer program COFECHA with a segment length of 50-year and 25-year overlaps; ${ }^{\text {, }}$, composite chronology in the western LLM (derived from samples sites of XXD, XLA, ZYD and WRH); ${ }^{\circ}$, composite chronology in the eastern LLM (derived from sample sites of CLA and CXL); ${ }^{\mathrm{d}}$, meteorological stations are selected for subsequent analyses.

\subsection{Statistical and periodicity analyses}

Correlation analyses were used to provide an estimate of the causal relationships between climate data and tree-ring chronologies (Fritts, 1976). A 16-moving window, from September of the previous year to December of the current year, was used to identify climate signals. Furthermore, because relationships between climate and tree growth might change over time under global warming (Briffa et al., 1998; D'Arrigo et al., 2008; Schneider et al., 2014); therefore, these relationships were tested for temporal change according to evolutionary interval correlation analyses by the software program DendroClim2002 (Biondi, 1997; Biondi and Waikul, 2004). Linear regression models between the predictors (tree-ring records) and the predictands were computed for the calibration period, and the models were validated by the rigorous split calibration-verification method in which the model was fitted to one half of the data and tested on the other half, including the coefficient of efficiency, the reduction of error and the product means test (Fritts, 1976; Cook et al., 1994). Additionally, the multi-taper method (MTM) of spectrum analysis was applied for periodicity analysis (Mann and Lees, 1996). MTM is used to evaluate frequency domains in local drought variability, which has proved to be a powerful tool in spectral estimation, especially for the analysis of short time series (Lees and Park, 1995). 


\section{Results}

\subsection{Regional chronologies and climate-growth relationships}

The regional tree-ring standardized chronologies, WLL or ELL, were developed from a total of 101 or 50 tree-ring width series. According to the EPS threshold value of 0.85 , reliable starting year of the WLL or ELL chronologies was 1786 or 1867, and 9 or 4 cores were present in 1786 or 1867. The high average series inter-correlation ( $r=0.60$ or 0.61$)$ indicated the presence of a strong common growth pattern. The high signal-to-noise percentage $(46.3 \%$ or $77.6 \%)$ suggested that the chronologies contained a variety of environmental information, and tree growth in study area was sensitive to the influence of external forces.

Although both WLL and ELL chronologies showed positive relationships with monthly precipitation, almost no significant correlations were found between WLL and monthly precipitation $(P<0.01$; Fig. 2). ELL was highly correlated with the precipitation of September of the previous year and March of the current year $(P<0.01$; Figs. 2a and b). In contrast, tree growth showed weaker inverse relationships with air temperature. There was only a significant negative correlation between WLL and mean temperature of August of the current year $(P<0.01 ;$ Fig. $2 \mathrm{c})$.

We used mean sc PDSI data from four grid points that showed the highest correlations with the WLL chronology, while the mean sc_PDSI data from the P1 and P2 grid points showed the highest correlations with the ELL chronology. All correlations with monthly sc_PDSI from September of the previous year to August of the current year were significantly positive $(P<0.01$; Fig. 2d), and correlations of WLL and ELL with sc_PDSI increased by seasonal data calculation as months were aggregated into seasons and were highest for the 12-month season grouping of the September of the previous year to the August of the current year (sc_PDSI PSA), with correlation coefficients were 0.675 and $0.652(P<0.001)$, respectively.
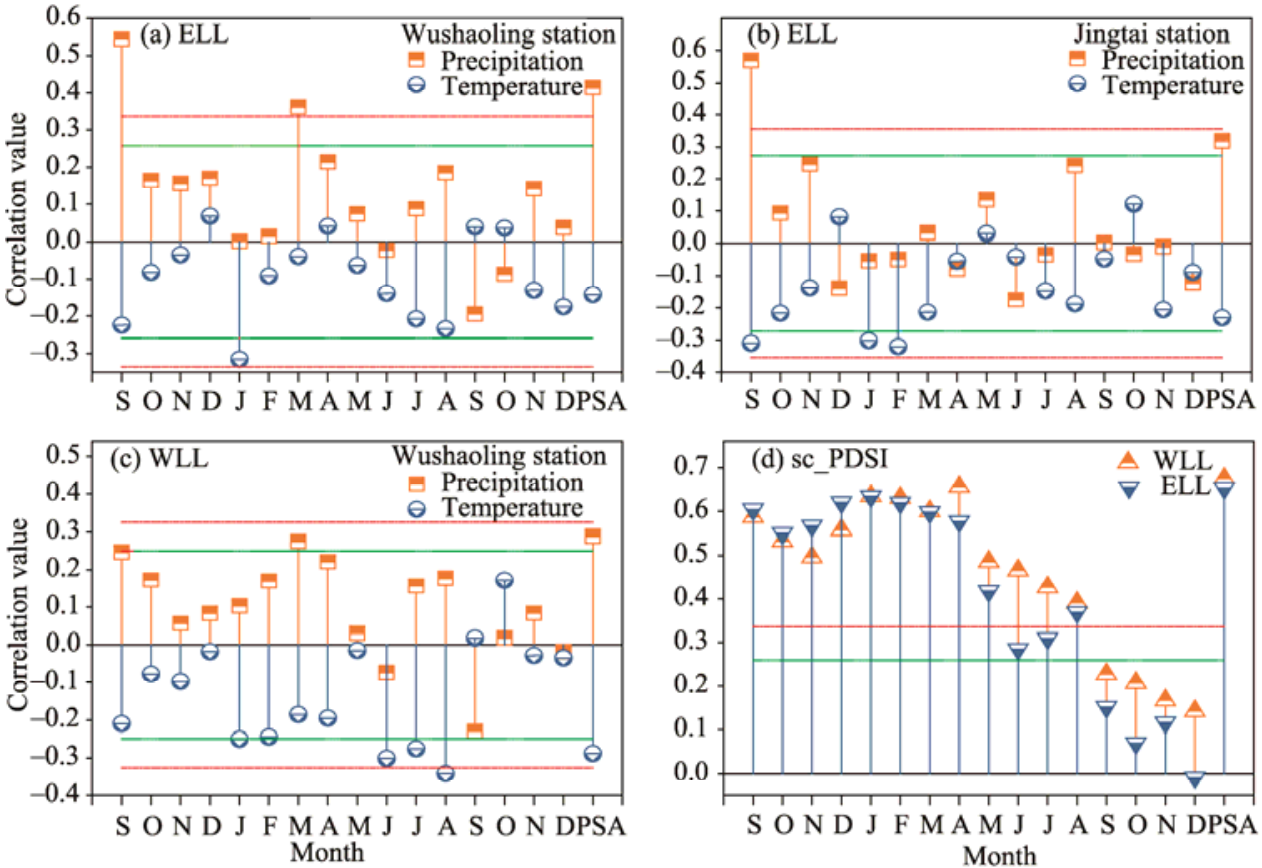

Fig. 2 Correlation analyses between tree-ring chronologies (WLL and ELL) and monthly climatic data (a-c) and self-calibrated Palmer Drought Severity Index (sc_PDSI; d). Green and red color lines indicate significance at $P<0.05$ and $P<0.01$ levels, respectively. PSA is the period from September of the previous year to August of the current year.

Temporal correlation coefficients of tree-ring indices and climatic factors were calculated by evolutionary intervals correlation functions (30-year moving window) in the program DendroClim2002 and plotted with color-coded symbols (Fig. 3; Biondi, 2000). The 
dendroclimatic relationships between WLL and monthly sc_PDSI from September of the previous year to August of the current year were stable and consistent during the entire period (Fig. 3a). The ELL chronology showed significant and stable temporal relationships with monthly sc_PDSI from September of the previous year to May of the current year over time (Fig. 3b).

In short, sc PDSI had more strong and stable temporal relationships with two tree-ring indices, indicating that a strong positive relationship with sc PDSI was the main climate signal in the two chronologies, and this might possibly be related to increased stress on tree growth as a result of increasing temperatures.
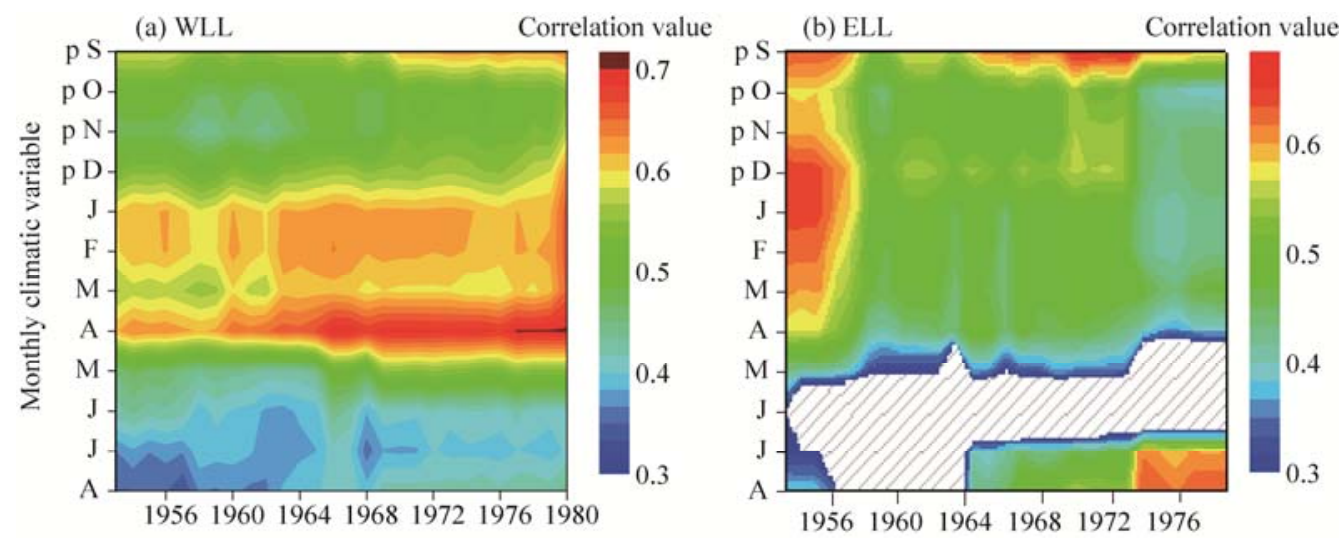

Fig. 3 Significant correlations $(P<0.05$ level) tree-ring chronologies $(\mathrm{a}$ and $\mathrm{b})$ and monthly sc_PDSI. Non-significant correlation values are set to zero (symbolization by white sparse grids). Vertical axis is selected monthly climatic variables from September of the previous year (p S) to August of the current year.

\subsection{Drought reconstructions}

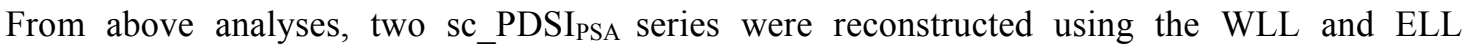
standardized chronologies as the predictors. Correlation coefficients for the split-sample validation periods were large and significant, and the reduction of error and coefficient of efficiency values were statistically significant for validation, which indicated the model skills were greater than zero (Cook et al., 1994; Table 2). The reconstructed series showed good low-frequency agreement and highly significant cross-correlation with the instrumental data series (Fig. 4). The statistical significance of the reconstructed models showed that tree-ring series provided well-adapted proxies for drought variations in the study area, and thus two drought series were reconstructed (Figs. 4a-d).

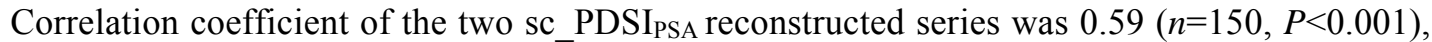
and a new sc_PDSI series (LLM) was used to reflect regional drought fluctuations for the LLM by using the arithmetic mean of the two reconstructed series (Fig. 4e). The mean value (m) and standard deviation $(\sigma)$ of LLM were -0.37 and 0.88 , respectively. Extremely dry $(<\mathrm{m}-2 \sigma)$ years were 1818, 1819, 1829, 1928, 1931, 2001 and 2013, and extremely wet years $(>\mathrm{m}+2 \sigma)$ were 1794 and 1954. Additionally, dry events with over three continuous dry $(<\mathrm{m}-1 \sigma)$ years were identified in 1817-1819, 1829-1831, 1928-1931 and 1999-2001, and humid events in 1792-1795 and 1954-1956 (Fig. 4e).

The results of MTM spectrum analyses showed that the reconstructions revealed significant high-frequency peaks at 8.33-year, 2.18-year, 2.00-year $(P<0.05)$ and 3.44-year, and at 2.63-year $(P<0.01)$ intervals in reconstruction based on the ELL chronology, and at 3.44-year, 2.90-year, 2.50-year $(P<0.05)$, and 4.17-year, 2.63-year $(P<0.01)$ intervals in reconstruction based on the WLL chronology (Fig. 5). Most inter-decadal periodicities fell within the overall range of variability in the El Niño-Southern Oscillation (ENSO; Torrence and Webster, 1999). The common periodicities (3.44-year and 2.63-year) in the two reconstructions analyzed here could be considered as the main climatic cycles in the LLM. Similar periodicities had also been previously 
Table 2 Calibration and verification statistics for the drought reconstructions

\begin{tabular}{|c|c|c|c|c|c|c|c|c|c|}
\hline $\begin{array}{l}\text { Calibration } \\
\text { periods }\end{array}$ & $\begin{array}{l}\text { Verification } \\
\text { periods }\end{array}$ & $R^{2}(\%)$ & $F$-value & $r$ & $\mathrm{RE}$ & $\mathrm{CE}$ & $t$-statistic & $\begin{array}{l}\text { Sign } \\
\text { test }\end{array}$ & $\begin{array}{l}\text { First-order } \\
\text { sign test }\end{array}$ \\
\hline \multicolumn{10}{|c|}{ Western Lenglongling Mountains } \\
\hline 1952-2009 & - & 45.8 & $47.3^{* *}$ & - & - & - & - & - & - \\
\hline 1981-2009 & $1952-1980$ & 59.7 & $40.0^{* *}$ & $0.64^{* *}$ & 0.267 & 0.264 & $2.87^{* *}$ & $19+/ 10-$ & $24+/ 4-^{* *}$ \\
\hline $1952-1980$ & 1981-2009 & 34.2 & $14.0^{* *}$ & $0.78^{* *}$ & 0.442 & 0.439 & $2.61^{* *}$ & $26+/ 3-^{* *}$ & $23+/ 5^{-* *}$ \\
\hline \multicolumn{10}{|c|}{ Eastern Lenglongling Mountains } \\
\hline 1952-2005 & - & 43.8 & $40.5^{* *}$ & - & - & - & - & - & - \\
\hline 1979-2005 & $1952-1978$ & 37.4 & $14.9^{* *}$ & $0.67^{* *}$ & 0.429 & 0.427 & $2.93^{* *}$ & $20+/ 7-^{*}$ & $23+/ 3-^{* *}$ \\
\hline $1952-1978$ & 1979-2005 & 45.3 & $20.7^{* *}$ & $0.61^{* *}$ & 0.296 & 0.29 & 2 & $20+/ 7-^{*}$ & $19+/ 7-^{*}$ \\
\hline
\end{tabular}

Note: RE: reduction of error; CE: coefficient of efficiency; " and ${ }^{* *}$ indicate significance at $P<0.05$ and $P<0.01$ levels, respectively. “-” indicates no value.

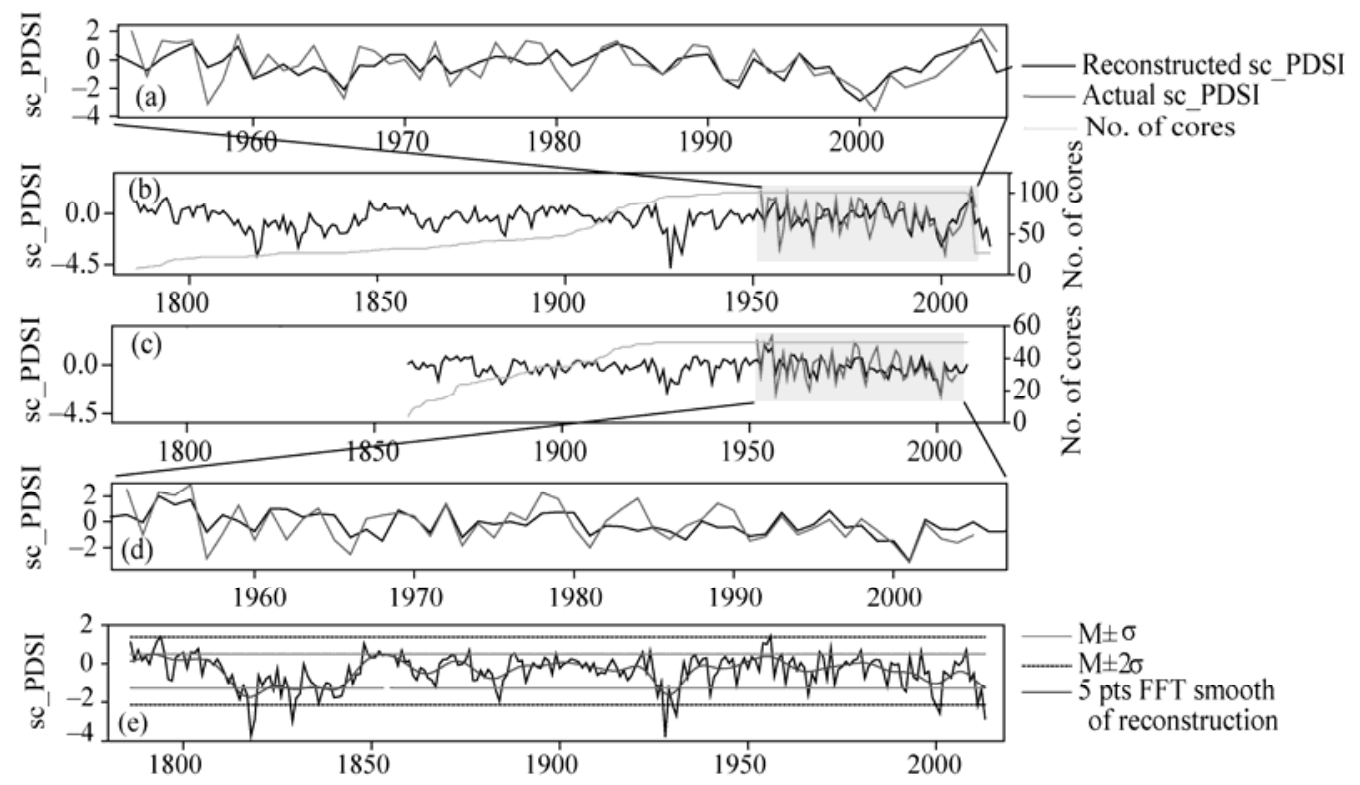

Fig. 4 Reconstructions of sc_PDSI based on WLL and ELL ring-width chronologies and their corresponding sample depths (a-d). A new sc_PDSI series (1786-2013) through arithmetic mean of the two reconstructed series (e). $M$ and $\sigma$ indicate mean value and standard deviation, respectively.
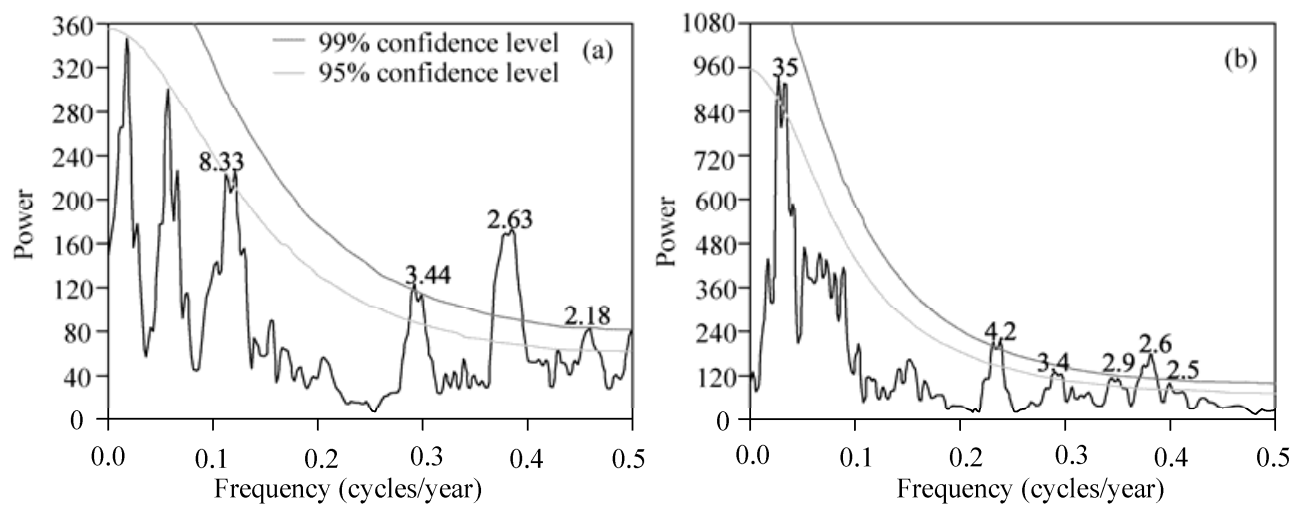

Fig. 5 Spectral densities of reconstructed series based on the ELL (a) and WLL (b) according to multi-taper method 
identified in the tree-ring based drought reconstructions in the Ortindag Sandy Land (Liang et al., 2007), Helan Mountains (Li et al., 2007), Xinglong Mountain (Fang et al., 2009), Guiqing Mountain (Fang et al., 2010), Kongtong Mountain (Fang et al., 2012) and the Loess Plateau of China (Chen et al., 2014). These similar inter-decadal periodicities suggested a strong connection between ENSO and large-scale drought fluctuations in northwestern margin of the EASM (Wang et al., 2000; Xue and Liu, 2008; Li et al., 2015).

\section{Discussion}

\subsection{Drought fluctuations in the northwestern margin of the EASM}

For better revealing large-scale drought patterns and their characteristics, we compared the drought reconstructions with various precipitation/drought reconstructions derived from tree ring data for the northwest margin of the EASM (T1-T14 records; Fig. 1). The occurrence of large-scale extreme dry/wet events in the monsoon boundary region was consistent, the extreme dry events (1817-1819, 1829-1831, 1928-1931 and 1999-2001) and the humid events (1954-1956) in this study were also identified in other tree-ring records (Fig. 6). These consistencies were further tested through spatial correlations between the reconstruction and other comparable drought series; except for the non-significant correlation between LLM and Hailer tree-ring record (T1; Fig. 7a), the other correlations between LLM and other tree-ring records were significant $(P<0.05$ or 0.01 level; T2-T10; Fig. 7a), with a mean correlation value of 0.33 $(P<0.01, n=134)$, and the correlation between LLM and the reconstruction in the north Helan Mountains was the strongest $(r=0.51, P<0.01$; T5; Fig. $7 \mathrm{a})$.

At a decadal scale, although some differences were observed in the reconstructed periods, long-term drought fluctuations of all 11-year low-pass filtering series were synchronous (Fig. 6). The first slowly descending period was from 1803 to 1835 , the second period was from 1892 to 1928 with a rapid decreasing trend from humid to extremely dry conditions (MS; Fig. 6). Another noteworthy feature was a remarkable decreasing trend of moisture conditions after the 1950s in the northwest margin of the EASM (Chen et al., 2013; Gao et al., 2013; Kang et al., 2014). This indicated that moisture conditions of the EASM had become weaker than before (Ding et al., 2008; Qian et al., 2009; Zhou and Huang, 2010; Li et al., 2015). In addition, this downward trend of moisture conditions had been linked to a trend of increasing temperatures in the late $20^{\text {th }}$ century in the margin area of the EASM (Liu et al., 2005; Cai et al., 2010; Chen et al., 2013; Li et al., 2013; Ma et al., 2016), and the continuation of this warming trend was likely to result in prolonged and extreme drought conditions.

All tree-ring reconstructed series (except the Hailer series) described a higher agreement at a decadal scale than that at an inter-annual scale. The mean correlation value of all low-frequency series increased to $0.5(P<0.01, n=124$; Fig. 7a), all correlations between LLM and other tree-ring records were significant $(P<0.01)$, and LLM showed the strongest correlation with the reconstructions in the Hengshan and Xinglong mountains, with a correlation value of 0.66 and 0.65, respectively (1870-1992; T4 and T7; Fig. 7a).

Tree growth in the margin areas of the EASM depended largely on moisture conditions (Qin et al., 2015), and atmospheric circulation systems affected precipitation in these areas (Torrence and Webster, 1999; Wang et al., 2000). Because of a weaker monsoon flow, sometimes the monsoon rainfall could not reach northern China, causing severe droughts in some years and vice versa (Ding et al., 2008; Qian et al., 2009; Zhou and Huang, 2010). Because of possible influences by similar external forcing, the inter-annual and especially the decadal, fluctuations of moisture conditions based on tree-ring records were synchronous over time in the northwestern margin of the EASM.

\subsection{Drought dynamics in arid region of the Northwest China}

In the $19^{\text {th }}$ century, there were significant positive correlations between LLM and four other series (Fig. 7a). The mean correlation value was $0.4(P<0.01)$, and the association between LLM and the reconstruction in the Tianshan Mountains was the strongest $(1817-1904 ; r=0.57, P<0.01$; T14; 
Fig. 7b). However, in the $20^{\text {th }}$ century the drought and humid periods were inconsistent in the arid regions of the Northwest China. This result was tested further by the smaller values of the spatial correlations during the period from 1905 to 2000 (Fig. 7b); the 1927-1931 drought period did not occur in the Tianshan Mountains, and 1949-1954 humid period only occurred in the Qilian Mountains which was significantly influenced by the Asian Monsoon (Fig. 8; Li et al., 2015).

At a decadal scale, LLM was significantly related to four other series showed by the spatial correlations $(P<0.01,1822-1995$; Fig. 7a). Before the 1950s, long-term drought fluctuations of all 11-year low-pass filtering series were synchronous in the arid region of the Northwest China (MS; Fig. 8), the mean correlation value of all low-frequency series increased to $0.44(P<0.01 ;$ Fig. $7 \mathrm{~b})$, and the correlation between LLM and the reconstruction in the western Qilian Mountains was the

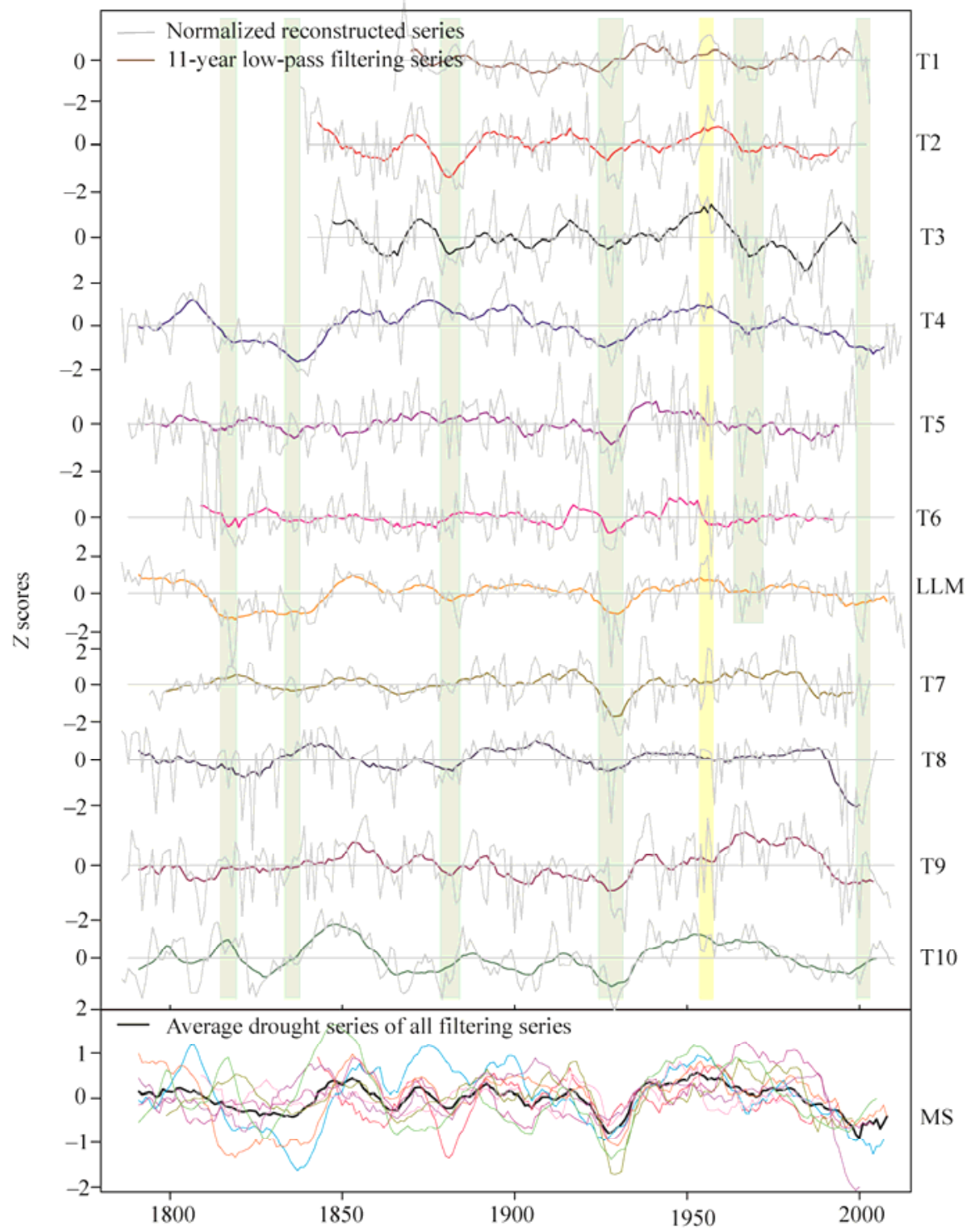

Fig. 6 Comparisons among various reconstructed series derived from tree rings. Drought reconstructions for: (T1) Hailar region (Liu et al., 2009); (T2) Baiyinaobao region (Liu et al., 2003); (T3) Ortindag Sandy Land (Liang et al., 2007); (T4) Hengshan Mountain (Cai et al., 2015); (T5) northern Helan Mountains (Li et al., 2007); (T6) southern Helan Mountains (Liu et al., 2004); (T7) Xinglong Mountain (Fang et al., 2009); (T8) Guiqing Mountain (Fang et al., 2010); (T9) Kongtong Mountain (Fang et al., 2012); (T10) Loess Plateau (Chen et al., 2014) and (LLM) Lenglongling Mountains (the present study); (MS) average drought series through arithmetic mean of all filtering series to emphasize long-term fluctuations in the northwestern margin of the EASM. 


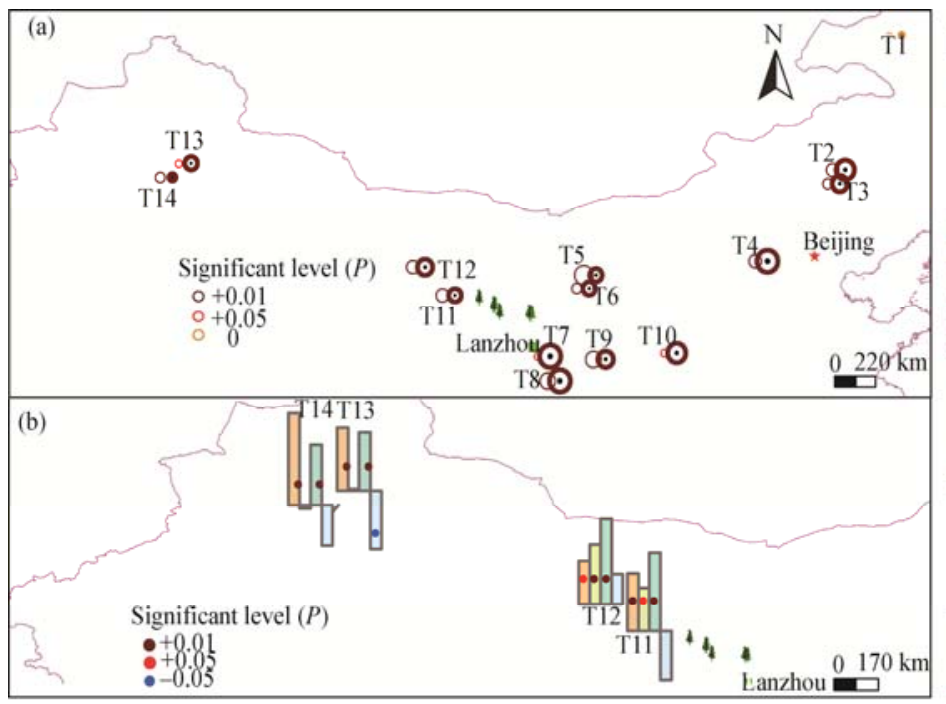

Legend

4 Tree-ring record (the present study)

O Correlation values

- Correlation values

(low-frequency series)

- $0-0.15$

- $0.15-0.22$

- $0.22-0.3$

ㅇ $0.3-0.4$

О $0.4-0.5$

O. $0.5-0.6$

O $0.6-0.7$

Legend

4 Tree-ring record (the present study)

$\square$ Correlation values (1817-1904)

$\square$ Correlation values (1905-2000)

$\square$ Correlation values

(low-frequency series, 1822-1954)

$\square$ Correlation values

(low-frequency series, 1955-1995)

Fig. 7 Spatial correlations between our series and other compared reconstructed series (T1-T14) during the period from 1865 to 1997 (a); and statistical histograms of correlation values between our reconstruction and other compared reconstructed series (T11-T14) in arid regions in Northwest China during different periods (b)

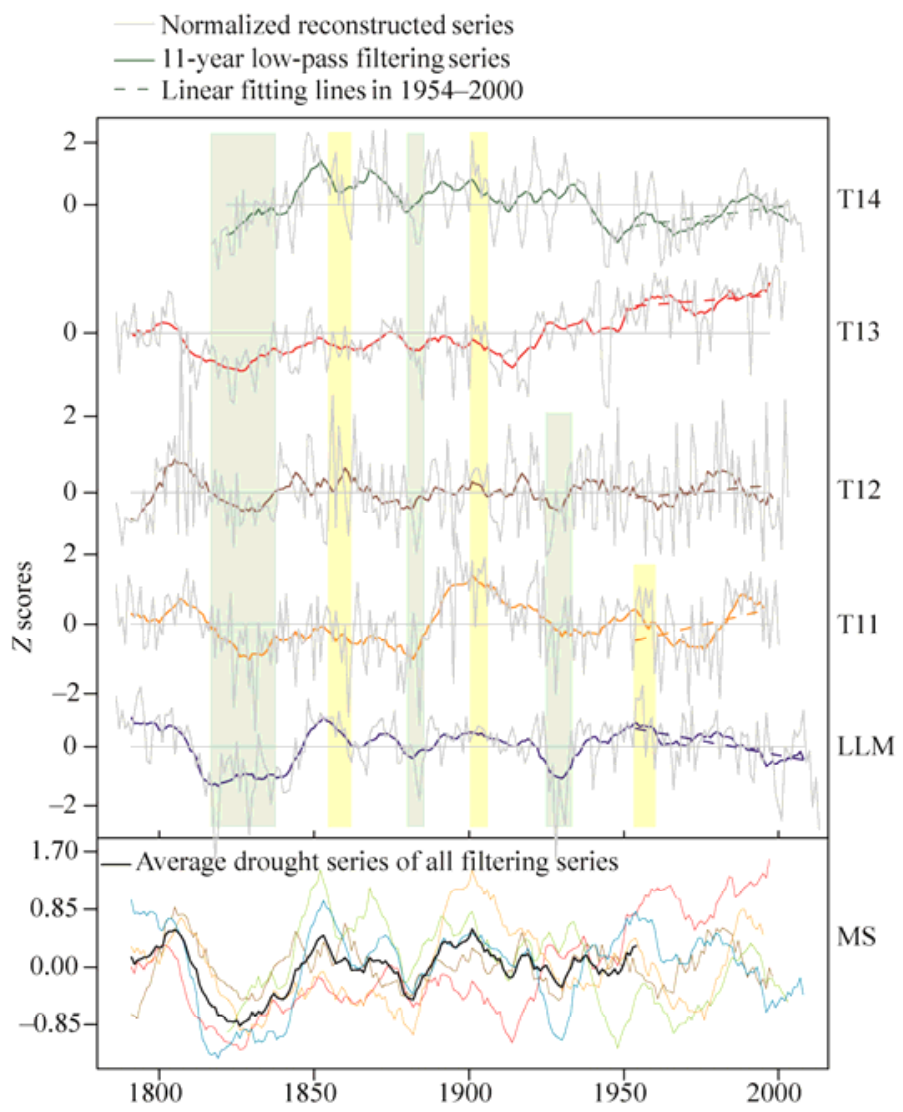

Fig. 8 Comparisons among various reconstructed series derived from tree rings. Drought reconstructions for: (T11) middle Qilian Mountains (Sun and Liu, 2012); (T12) western Qilian Mountains (Liang et al., 2009); (T13) Tianshan Mountains (Li et al., 2006); (T14) Tianshan Mountains (Xu et al., 2014) and (LLM) Lenglongling Mountains (the present study). (MS) average drought series through arithmetic mean of all filtering series to emphasize long-term fluctuations (1786-1954) in arid region of Northwest China. 
strongest $(1822-1954 ; r=0.53, P<0.01 ;$ T12; Fig. 7b). However, after the $1950 \mathrm{~s}$, moisture conditions were consistently increasing in the Xinjiang region (T13, T14; Fig. 8; Zhang et al., 2013; Chen et al., 2015; Wang et al., 2015), and were significantly increasing in the western and middle Qilian Mountains (T11 and T12; Fig. 8; Liu et al., 2009; Gou et al., 2015b). In contrast, moisture conditions in the LLM presented an opposite trend (LLM; Fig. 8), and this opposite trend was further tested through negative correlations between LLM and three other series. In addition, LLM was significantly negatively associated with the Palmer Drought Severity Index (PDSI) series in the Tianshan Mountains (1955-1995; $r=-0.36, P<0.05$; Fig. 7b).

Studies based on meteorological data indicated that the western part of northwestern China has become wet after the previous dry conditions, whereas in the eastern part of northwestern China has become drier after the previous wet periods in recent decades (Shi et al., 2007; Wang et al., 2015; $\mathrm{Xu}$ et al., 2015). Although drought fluctuations referred from tree-ring records in the eastern and western parts of the Northwest China also showed these different trends in the past few decades, the long-term variability of moisture conditions was synchronous before the 1950s at a decadal scale (1791-1954) across the arid region of northwestern China. However, this synchronization of drought-wet fluctuations became weaker and more complicated than that in the northwestern margin of the EASM due to the climate in northwestern China was affected by multiple atmospheric circulation systems (Zhang et al., 2008; Li et al., 2011).

\section{Conclusions}

The results of correlation analyses showed that all standardized chronologies had much stronger correlations with sc_PDSI than those with only precipitation or temperature. Temporal correlation analyses using evolutionary intervals correlation functions revealed that the relationships between the two chronologies and sc_PDSI were stable for temporal change, indicating a tree-growth pattern of increasing moisture-stress in LLM. Sc_PDSIPSA was considered as the most appropriate predict and for drought reconstructions and tree-ring data from the LLM were used to reconstruct drought fluctuations over 1786-2013. By comparing the available drought reconstructions in the northwestern margin of the EASM and arid regions of the Northwest China, most of all selected drought series in the northwestern margin of the EASM had better consistency in high-frequency, especially in low-frequency variation, which could be demonstrated by similar inter-decadal periodicities revealed in reconstructions in the northwestern margin of the EASM. Meanwhile, although drought fluctuations in the eastern and western parts of Northwest China exhibited opposite trends in the past few decades, the long-term variability of moisture conditions was synchronous before the 1950s at a decadal scale across the arid regions of the Northwest China, which indicated a spatial and temporal correlation between local moisture conditions and large-scale moisture variations. Future studies reconstructing drought series of longer time spans and larger areas of spatial coverage are needed for better understanding the regional drought regimes and their forcing mechanisms.

\section{Acknowledgements}

The study was funded by the National Natural Science Foundation of China (51309134), the National Science Foundation for Fostering Talents in Basic Research of the National Natural Science Foundation of China (J1210065), the Research Starting Funds for Imported Talents, Ningxia University (BQD2012011) and the Natural Science Funds, Ningxia University (ZR1233). The authors thank CHENG Hongyi, HUANG Yinzhou, ZHAO Liqiang, CHENG Hongbao, LI Mingzhi, LAI Rongsheng, SU Xianbao and YANG Anning for their kind help with the field and laboratory work. We also thank FANG Keyan and two anonymous reviewers for their valuable comments and suggestions.

\section{References}

Biondi F. 1997. Evolutionary and moving response functions in dendroclimatology. Dendrochronologia, 15: $139-150$.

Biondi F. 2000. Are climate-tree growth relationships changing in north-central Idaho, U.S.A.? Arctic, Antarctic, and Alpine Research, 32(2): 111-116. 
Biondi F, Waikul K. 2004. DENDROCLIM2002: A C++ program for statistical calibration of climate signals in tree-ring chronologies. Computers \& Geosciences, 30(3): 303-311.

Briffa K R, Schweingruber F H, Jones P D, et al. 1998. Trees tell of past climates: but are they speaking less clearly today?. Philosophical Transactions of the Royal Society B: Biological Sciences, 353(1365): 65-73.

Büntgen U, Brázdil R, Frank D, et al. 2010. Three centuries of Slovakian drought dynamics. Climate Dynamics, 35(2-3): 315-329.

Cai Q F, Liu Y, Bao G, et al. 2010. Tree-ring-based May-July mean temperature history for Lüliang Mountains, China, since 1836. Chinese Science Bulletin, 55(26): 3008-3014.

Cai Q F, Liu Y, Liu H, et al. 2015. Reconstruction of drought variability in North China and its association with sea surface temperature in the joining area of Asia and Indian-Pacific Ocean. Palaeogeography, Palaeoclimatology, Palaeoecology, 417: 554-560.

Chen F, Yuan Y J, Wei W S, et al. 2013. Reconstructed precipitation for the north-central China over the past 380 years and its linkages to East Asian summer monsoon variability. Quaternary International, 283: 36-45.

Chen F, Yuan Y J, Zhang R B, et al. 2014. A tree-ring based drought reconstruction (AD 1760-2010) for the Loess Plateau and its possible driving mechanisms. Global and Planetary Change, 122: 82-88.

Chen F, Yuan Y J, Wei W S, et al. 2015. Tree-ring recorded hydroclimatic change in Tienshan Mountains during the past 500 years. Quaternary International, 358: 35-41.

Chen Z J, Zhang X L, He X Y, et al. 2013. Extension of summer (June-August) temperature records for northern Inner Mongolia (1715-2008), China using tree rings. Quaternary International, 283: 21-29.

Cook E R, Peters K. 1981. The smoothing spline: a new approach to standardizing forest interior tree-ring width series for dendroclimatic studies. Tree-Ring Bulletin, 41: 45-53.

Cook E R, Holmes R L. 1984. User's Manual for Program ARSTAN. Tucson: University of Arizona.

Cook E R, Kairiukstis L A. 1990. Methods of Dendrochronology: Applications in the Environmental Sciences. Netherlands: Springer.

Cook E R, Briffa K R, Jones P D. 1994. Spatial regression methods in dendroclimatology: a review and comparison of two techniques. International Journal of Climatology, 14(4): 379-402.

Cook E R, Meko D M, Stahle D W, et al. 1999. Drought reconstructions for the continental United States. Journal of Climate, 12(4): 1145-1162.

Cook E R, Woodhouse C A, Eakin C M, et al. 2004. Long-term aridity changes in the western United States. Science, 306(5698): 1015-1018.

Dai A G, Trenberth K E, Qian T T. 2004. A global dataset of Palmer drought severity index for 1870-2002: relationship with soil moisture and effects of surface warming. Journal of Hydrometeorology, 5(6): 1117-1130.

Dai A G. 2012. Increasing drought under global warming in observations and models. Nature Climate Change, 3(1): 52-58.

D'Arrigo R, Wilson R, Liepert B, et al. 2008. On the "Divergence Problem" in northern forests: a review of the tree-ring evidence and possible causes. Global and Planetary Change, 60(3-4): 289-305.

Deng Y, Gou X H, Gao L L, et al. 2013. Aridity changes in the eastern Qilian Mountains since AD 1856 reconstructed from tree-rings. Quaternary International, 283: 78-84.

Ding Y H, Wang Z Y, Sun Y. 2008. Inter-decadal variation of the summer precipitation in East China and its association with decreasing Asian summer monsoon. Part I: Observed evidences. International Journal of Climatology, 28(9): 1139-1161.

Fang K Y, Gou X H, Chen F H, et al. 2009. Drought variations in the eastern part of northwest China over the past two centuries: evidence from tree rings. Climate Research, 38(2): 129-135.

Fang K Y, Gou X H, Chen F H, et al. 2010. Tree-ring based drought reconstruction for the Guiqing Mountain (China): linkages to the Indian and Pacific Oceans. International Journal of Climatology, 30(8): 1137-1145.

Fang K Y, Gou X H, Chen F H, et al. 2012. Tree-ring based reconstruction of drought variability (1615-2009) in the Kongtong Mountain area, northern China. Global and Planetary Change, 80-81: 190-197.

Fritts H C. 1976. Tree Rings and Climate. Caldwell, New Jersey: Blackburn Press.

Gao J X, Shi Z J, Xu L H, et al. 2013. Precipitation variability in Hulunbuir, northeastern China since 1829 AD reconstructed from tree-rings and its linkage with remote oceans. Journal of Arid Environments, 95: 14-21.

Gou X H, Deng Y, Gao L L, et al. 2015a. Millennium tree-ring reconstruction of drought variability in the eastern Qilian Mountains, northwest China. Climate Dynamics, 45(7-8): 1761-1770.

Gou X H, Gao L L, Deng Y, et al. 2015b. An 850-year tree-ring-based reconstruction of drought history in the western Qilian Mountains of northwestern China. International Journal of Climatology, 35(11): 3308-3319.

Holmes R L. 1983. Computer-assisted quality control in tree-ring dating and measurement. Tree-Ring Bulletin, 43: 69-78. 
Kang S Y, Bräuning A, Ge H Y. 2014. Tree-ring based evidence of the multi-decadal climatic oscillation during the past 200 years in north-central China. Journal of Arid Environments, 110: 53-59.

Lees J M, Park J. 1995. Multiple-taper spectral analysis: a stand-alone c-subroutine. Computers \& Geosciences, 21(2): 199-236.

Leng G Y, Tang Q H, Rayburg S. 2015. Climate change impacts on meteorological, agricultural and hydrological droughts in China. Global and Planetary Change, 126: 23-34.

Li J B, Gou X H, Cook E R, et al. 2006. Tree-ring based drought reconstruction for the central Tien Shan area in northwest China. Geophysical Research Letters, 33: L07715, doi: 10.1029/2006GL025803.

Li J B, Chen F H, Cook E R, et al. 2007. Drought reconstruction for North Central China from tree rings: the value of the Palmer drought severity index. International Journal of Climatology, 27(7): 903-909.

Li Q, Liu Y, Song H M, et al. 2013. Long-term variation of temperature over North China and its links with large-scale atmospheric circulation. Quaternary International, 283: 11-20.

Li X Q, Zhao K L, Dodson J, et al. 2011. Moisture dynamics in central Asia for the last 15 kyr: new evidence from Yili Valley, Xinjiang, NW China. Quaternary Science Reviews, 30(23-24): 3457-3466.

Li Z X, Gao Y, Wang Y M, et al. 2015. Can monsoon moisture arrive in the Qilian Mountains in summer?. Quaternary International, 358: 113-125.

Liang E Y, Shao X M, Liu H Y, et al. 2007. Tree-ring based PDSI reconstruction since AD 1842 in the Ortindag Sand Land, east Inner Mongolia. Chinese Science Bulletin, 52(19): 2715-2721.

Liang E Y, Shao X M, Liu X H. 2009. Annual precipitation variation inferred from tree rings since A.D. 1770 for the western Qilian Mts., northern Tibetan Plateau. Tree-Ring Research, 65(2): 95-103.

Liu W H, Gou X H, Yang M X, et al. 2009. Drought reconstruction in the Qilian Mountains over the last two centuries and its implications for large-scale moisture patterns. Advances in Atmospheric Sciences, 26(4): 621-629.

Liu X H, Qin D H, Shao X M, et al. 2005. Temperature variations recovered from tree-rings in the middle Qilian Mountain over the last millennium. Science China Series D: Earth Sciences, 48(4): 521-529.

Liu Y, Cai Q F, Won-Kyu P, et al. 2003. Tree-ring precipitation records from Baiyinaobao, Inner Mongolia since A.D. 1838. Chinese Science Bulletin, 48(11): 1140-1145.

Liu Y, Ma L M, Leavitt S W, et al. 2004. A preliminary seasonal precipitation reconstruction from tree-ring stable carbon isotopes at Mt. Helan, China, since AD 1804. Global and Planetary Change, 41(3-4): 229-239.

Liu Y, Cai Q F, Liu W G, et al. 2008. Monsoon precipitation variation recorded by tree-ring $\delta^{18} \mathrm{O}$ in arid Northwest China since AD 1878. Chemical Geology, 252(1-2): 56-61.

Liu Y, Bao G, Song H M, et al. 2009. Precipitation reconstruction from Hailar pine (Pinus sylvestris var. mongolica) tree rings in the Hailar region, Inner Mongolia, China back to 1865 AD. Palaeogeography, Palaeoclimatology, Palaeoecology, 282(1-4): 81-87.

Ma L, Liu T X, Wang J R, et al. 2016. Determining changes in the average minimum winter temperature of Horqin Sandy Land using tree ring records. Theoretical and Applied Climatology, 123(3): 703-710, doi: 10.1007/s00704-015-1382-5.

Mann M E, Lees J M. 1996. Robust estimation of background noise and signal detection in climatic time series. Climatic Change, 33(3): 409-445.

Nicault A, Alleaume S, Brewer S, et al. 2008. Mediterranean drought fluctuation during the last 500 years based on tree-ring data. Climate Dynamics, 31(2-3): 227-245.

Palmer W C. 1965. Meteorological Drought. Research Paper No. 45. Washington D. C.: U. S. Department of Commerce Weather Bureau.

Peng J F, Liu Y Z. 2013. Reconstructed droughts for the northeastern Tibetan Plateau since AD 1411 and its linkages to the Pacific, Indian and Atlantic Oceans. Quaternary International, 283: 98-106.

Qian W H, Ding T, Hu H R, et al. 2009. An overview of dry-wet climate variability among monsoon-westerly regions and the monsoon northernmost marginal active zone in China. Advances in Atmospheric Sciences, 26(4): 630-641.

Qin C, Yang B, Bräuning A, et al. 2015. Drought signals in tree-ring stable oxygen isotope series of Qilian juniper from the arid northeastern Tibetan Plateau. Global and Planetary Change, 125: 48-59.

Rinn F. 2003. TSAP-Win User Reference (version 0.53). Heidelberg: Rinntech Company.

Schneider L, Esper J, Timonen M, et al. 2014. Detection and evaluation of an early divergence problem in northern Fennoscandian tree-ring data. Oikos, 123(5): 559-566.

Shi Y F, Shen Y P, Kang E S, et al. 2007. Recent and future climate change in Northwest China. Climatic Change, 80(3-4): 379-393.

Su X L, Li J F, Singh V P. 2014. Optimal allocation of agricultural water resources based on virtual water subdivision in 
Shiyang River Basin. Water Resources Management, 28(8): 2243-2257.

Sun J Y, Liu Y. 2012. Tree ring based precipitation reconstruction in the south slope of the middle Qilian Mountains, northeastern Tibetan Plateau, over the last millennium. Journal of Geophysical Research: Atmospheres, 117(D8): D8108.

Tang X, Sun G W, Qian W H. 2007. The Research of the Northern Fringe of Asian Summer Monsoon. Beijing: China Meteorological Press, 25-48. (in Chinese)

Tei S, Yonenobu H, Suzuki S, et al. 2015. Reconstructed July temperatures since AD 1800, based on a tree-ring chronology network in the Northwest Pacific region, and implied large-scale atmospheric-oceanic interaction. Palaeogeography, Palaeoclimatology, Palaeoecology, 435: 203-209.

Tian Q H, Gou X H, Zhang Y, et al. 2009. May-June mean temperature reconstruction over the past 300 years based on tree rings in the Qilian Mountains of the northeastern Tibetan Plateau. IAWA Journal, 30(4): 421-434.

Torrence C, Webster P J. 1999. Interdecadal changes in the ENSO-monsoon system. Journal of Climate, 12(8): 2679-2690.

Wang B, Wu R G, Fu X H. 2000. Pacific-East Asian teleconnection: how does ENSO affect East Asian climate?. Journal of Climate, 13(9): 1517-1536.

Wang T. 2004. Progress in sandy desertification research of China. Journal of Geographical Sciences, 14(4): $387-400$.

Wang T, Ren G Y, Chen F, et al. 2015. An analysis of precipitation variations in the west-central Tianshan Mountains over the last 300 years. Quaternary International, 358: 48-57.

Wang X M, Yang Y, Dong Z B, et al. 2009. Responses of dune activity and desertification in China to global warming in the twenty-first century. Global and Planetary Change, 67(3-4): 167-185.

Wang Y J, Chen X Y, Yan F. 2015. Spatial and temporal variations of annual precipitation during 1960-2010 in China. Quaternary International, 380-381: 5-13.

Wigley T M L, Briffa K R, Jones P D. 1984. On the Average value of correlated time series, with applications in dendroclimatology and hydrometeorology. Journal of Climate and Applied Meteorology, 23(2): 201-213.

Xu C C, Li J X, Zhao J, et al. 2015. Climate variations in northern Xinjiang of China over the past 50 years under global warming. Quaternary International, 358: 83-92.

Xu G B, Liu X H, Qin D H, et al. 2014. Drought history inferred from tree ring $\delta^{13} \mathrm{C}$ and $\delta^{18} \mathrm{O}$ in the central Tianshan Mountains of China and linkage with the North Atlantic Oscillation. Theoretical and Applied Climatology, 116(3-4): 385-401.

Xue F, Liu C Z. 2008. The influence of moderate ENSO on summer rainfall in eastern China and its comparison with strong ENSO. Chinese Science Bulletin, 53(5): 791-800.

Yang B, Qin C, Shi F, et al. 2012. Tree ring-based annual streamflow reconstruction for the Heihe River in arid northwestern China from AD 575 and its implications for water resource management. The Holocene, 22(7): 773-784.

Yang B, Kang S Y, Ljungqvist F C, et al. 2014. Drought variability at the northern fringe of the Asian summer monsoon region over the past millennia. Climate Dynamics, 43(3-4): 845-859.

Zhang Q, Zhang J, Sun G W, et al. 2008. Research on water-vapor distribution in the air over Qilian Mountains. Acta Meteorologica Sinica, 22(1): 107-118. (in Chinese)

Zhang T W, Yuan Y J, Liu Y, et al. 2013. A tree-ring based precipitation reconstruction for the Baluntai region on the southern slope of the central Tien Shan Mountains, China, since A.D. 1464. Quaternary International, 283: 55-62.

Zhang Y, Tian Q H, Gou X H, et al. 2011. Annual precipitation reconstruction since AD 775 based on tree rings from the Qilian Mountains, northwestern China. International Journal of Climatology, 31(3): 371-381.

Zhao Y, Yu Z C. 2012. Vegetation response to Holocene climate change in East Asian monsoon-margin region. Earth-Science Reviews, 113(1-2): 1-10.

Zhou L T, Huang R H. 2010. Interdecadal variability of summer rainfall in Northwest China and its possible causes. International Journal of Climatology, 30(4): 549-557.

Zhu Q, Li Y. 2014. Environmental restoration in the Shiyang River Basin, China: conservation, reallocation and more efficient use of water. Aquatic Procedia, 2: 24-34. 